\title{
Marine mammal bycatch in Spanish Mediterranean large pelagic longline fisheries, with a focus on Risso's dolphin (Grampus griseus)
}

\author{
David Macías LóPEZ ${ }^{\text {a }}$, Salvador García BARcelona, José Carlos BÁEZ, José Miguel DE LA SERnA \\ and José María ORTIZ DE URBINA
}

Centro Oceanográfico de Málaga, Instituto Español de Oceanografía, Puerto pesquero, s/n, 29640 Fuengirola, Spain

Received 23 January 2012; Accepted 26 October 2012

\begin{abstract}
The western Mediterranean is an important fishing area in which the Spanish longline fleet operates. Longline fisheries affect several species of marine mammals, sea turtles, sharks and seabirds, all of which are especially sensitive to fishing mortality. Given international efforts to identify and reduce the bycatch of sensitive species, an onboard observer program was implemented by the Spanish Oceanographic Institute (IEO, Instituto Español de Oceanografía). The aim of the present study was to report data on marine mammal bycatch in the western Mediterranean. The additional aim was to improve knowledge about the possible effects of the Spanish longline fisheries on cetacean populations, particularly Risso's dolphin, and to suggest improvements to fisheries management. Data on marine mammal bycatch were collected during the period 2000-2009. Differences are reported for catch per unit effort (CPUE, defined as marine mammals per 1000 hooks) for each type of gear $(n=7)$, as well as their effect on specific marine mammal species. A total of 5398297 hooks were monitored, which yielded 56 marine mammals belonging to 4 different species. Our results indicate that Risso's dolphin is the species most affected by the longline fishery in the western Mediterranean $(n=33)$. We built a predictive model for Risso's dolphin bycatch using variables associated with the technical characteristics of the fishery, geographic location and seasonality. We performed a binary logistic regression of the presence/absence of Risso's dolphin bycatch to test whether the probability of incidentally catching one or more dolphins may be predicted by some of the explanatory variables selected. Our results indicate that Risso's dolphin was mainly caught using Japanese longline (LLJAP) or an experimental home-based longline (LLHBexp) over the continental shelf. Because LLHBexp is an experimental type of gear that was only used occasionally by the fleet, controlling the use of LLJAP over the continental shelf could strongly reduce the impact of these fisheries on populations of Risso's dolphin in the western Mediterranean.
\end{abstract}

Keywords: Bycatch / Cetaceans / CPUE / Pelagic longline / Mediterranean Sea

\section{Introduction}

Incidental catch, or bycatch, is defined as any unwanted species caught during normal fishing operations and may include threatened long-lived species such as marine mammals, turtles, sharks and seabirds (Hall 1996; Alverson 1999). Bycatch in certain fisheries represents a significant threat to the conservation of marine mammal populations, such as spotted and spinner dolphin (Stenella attenuata and S. longirostris) in the purse seine fishery in the Pacific Ocean (Gerrodette and Forcada 2005). Nevertheless, longline fisheries have been traditionally defined as having a low impact on marine mammals. Therefore, bycatch by drifting longlines (i.e., longlines set without a fixed anchorage) is not considered an important

a Corresponding author: david.macias@ma.ieo.es threat to the conservation of marine mammal species compared to other fisheries, such as purse seine or trawl (e.g., Tudela 2004), or to other longline bycatch species such as sea turtles (Camiñas et al. 2006).

The western Mediterranean Sea is an important fishing ground for the Spanish drifting longline fishery, which mainly targets swordfish Xiphias gladius, bluefin tuna Thunnus thynnus, and albacore T. alalunga. This fleet changes its gear and target species according to the season, economic profit or competition with other vessels. The fleet uses six different types of longline gear, which differ mainly by hook type and hook size, bait type and operational depth (for a detailed review see Camiñas et al. 2006; Báez et al. 2007a,b; García-Barcelona et al. 2010a,b). The Balearic Islands and surrounding fishing grounds are also important feeding areas for 
turtles and cetaceans (Valeiras and Camiñas 2002) but scientific data on marine mammal bycatch in the western Mediterranean are scarce, despite the importance of this fishing area for the Spanish pelagic longline fleet. Due to the spatial overlap between the fishing activity and vulnerable species (such as cetaceans, seabirds, sharks and turtles) the Spanish Institute of Oceanography (IEO) instituted an onboard observer program with the aim of obtaining direct information on catches and discards of target and bycatch species.

Of the 17 species of marine mammals cited in the Mediterranean (Duguy 1983a; Tudela 2004), bycatch in these fisheries mainly affects striped dolphin (S. coeruleoalba), false killer whale (Pseudorca crassidens), Risso's dolphin (Grampus griseus) (Duguy 1983b; Tudela 2004), common dolphins (Delphinus delphis) and pilot whales (Globicephala melas) (University of Barcelona 1995; Tudela 2004). According to these direct observations, Risso's dolphin appears to be the most frequent cetacean species in the bycatch of this fishery. Bearzi et al. (2011) pointed out that there is little information available on this species in the Mediterranean, and that more studies on Risso's dolphin in this area are needed.

Risso's dolphin is widely distributed and inhabits deep oceanic and continental slope waters at a depth of 400-1000 m (Baird 2002), and ranges from the tropics to temperate regions in both hemispheres, including the Mediterranean Sea (Jefferson et al. 1993). This species frequents mesopelagic areas, where dolphins mainly feed on mesopelagic cephalopods. The population density of the species in this area has been estimated at 0.015 dolphins per $\mathrm{km}^{2}$ (Gomez de Segura et al. 2006). Although its distribution covers a wide oceanic area, some authors have shown Risso's dolphin to be mainly associated with continental slopes (Mangion 2002).

Although Risso's dolphin is classified as being of "least concern" on the IUCN Redlist (www.uicnredlist.org), this species is the marine mammal most often incidentally captured by the Spanish longline fleet operating in the western Mediterranean Sea. Modelling the abundance of Risso's dolphin bycatch based on technical, geographic and seasonality factors could be of help regarding its management. If we select those variables that mainly affect the abundance of this bycatch and manage them efficiently, we could strongly decrease the impact of this fishery on the populations of the species. For example, if it was found that a seasonal variable, such as a specific month, was associated with the highest capture of Risso's dolphin, then managing this variable (i.e., by a temporary ban) could strongly reduce the bycatch. Thus, identifying the main factors determining this bycatch and how they can be controlled is a major goal for the conservation of this species.

The main aim of this paper was to describe the bycatch of marine mammals in the Spanish Mediterranean longline fleet. Following the recommendations of Bearzi et al. (2011), we also modelled the abundance and distribution of Risso's dolphin bycatch based on technical, geographic and seasonality factors. An additional aim of this study was to improve our knowledge about the possible effects of longline fisheries on cetacean populations, particularly Risso's dolphin, and to use this information to improve fisheries management to reduce negative impacts on the population.

\section{Materials and methods}

\subsection{Data collection}

We studied the Spanish longline vessels targeting highly migratory species, such as tuna and swordfish. The bottom longline artisanal fleet targeting Merluccius sp. was not studied. During the study period, this fleet consisted of approximately 90 vessels (annual average) that fished throughout the year. These vessels are very homogeneous, with lengths ranging from $12 \mathrm{~m}$ to $27 \mathrm{~m}$, and fishing trips were often of short duration (1 to 6 days). In addition, each individual vessel changes the type of gear and target species based on season, economic profit, or competition with other vessels. The fishing grounds cover a large area of the western Mediterranean basin, between $36^{\circ} \mathrm{N}$ and $44^{\circ} \mathrm{N}$ and $02^{\circ} \mathrm{W}$ and $05^{\circ} \mathrm{E}$. Recent studies have described these fleets in detail (Valeiras and Camiñas 2003; Camiñas et al. 2006; Báez et al. 2006, 2007a,b, 2009; García-Barcelona et al. 2010a,b; Báez et al. 2010, 2011), of which a short synopsis follows (gear codes according to the International Commission for the Conservation of Atlantic Tunas (ICCAT)).

- Home-based longline (LLHB). The length of traditional surface longlines targeting swordfish is variable, ranging from 37 to $65 \mathrm{~km}$. The main line hangs from floats and information recorded by depth sensors indicates that the average depth of surface hooks is $30 \mathrm{~m}$ (maximum depth $50 \mathrm{~m}$ ). The hooks used are J-shaped Mustad number 2 (approximately $7.5 \times 2.5 \mathrm{~cm}$ ), usually baited with mackerel (Scomber sp.) and squid (Illex sp.). This gear is used throughout the year.

- American longline (LLAM). Hydraulically-operated monofilament longline reel (commonly known as the "American roller") is a type of gear imported from the Italian and American long-liners in the early 2000s (Báez et al. 2006). Unlike the traditional longline, it employs a hydraulic reel to pick up the mainline, which is often placed at the stern of the boat. Monofilament longlines reach 90 to $100 \mathrm{~km}$ in length with fewer hooks than LLHB, implying a greater distance between each hook. Fishing depth is greater, with the deepest hooks working at $70 \mathrm{~m}$ below the surface. This gear is used throughout the year.

- Japanese longline (LLJAP). This is a monofilament longline used exclusively during the months of May, June and the first half of July, which is the period when bluefin tuna enter the Mediterranean to breed. The differences between this gear and the swordfish monofilament longline are that the fishing depth is greater, the bait is almost always squid (Illex sp.) larger than $500 \mathrm{~g}$, and the gear remains in use for periods of 24 hours. LLJAP typically uses a C-shaped hook.

- Longline targeting albacore (LLALB). This is the shallowest longline gear. Both the size of the hook and the thickness and length of the fishing lines are less than other longlines.

- Semipelagic longline (LLSP, not included in ICCAT codes). This is a hydraulically-operated monofilament longline reel (commonly known as the "American roller"). Unlike the LLAM, it includes weights and buoys so that 
the mainline floats in the middle of the water column, thus increasing the fishing depth.

- Bottom longline (LLPB, palangre piedra y bola in Spanish). This gear is a variant of the bottom longline targeting silver scabbardfish. It consists of a longline similar to LLHB, but fixed at the bottom by means of a few weights interspersed between floats.

- Experimental home-based longline targeting swordfish (LLHBexp). Additionally, we observed several sets of LLHB that resemble the fishing depth and bait used in LLAM, using small weights on the branchline. We included these sets as a different new experimental gear because they cannot be strictly included in LLHB.

In 1999, the IEO established an onboard observer program in commercial longline fisheries. This program provided commercial fish catch and bycatch data collected on longline vessels from 1999 to 2009. Observers were assigned based on the type of gear used. For each fishing set observed, data were recorded on: fishing set location; time of setting and hauling; environmental data (sea surface temperature, distance to the coast, depth and weather conditions, moon phase); soaking duration; gear characteristics (total length, mean depth, number of hooks, etc.); type and size of bait; species composition; and corresponding biological information (size/weight). For each set sampled, the observers monitored $100 \%$ of the total hooks retrieved and recorded information on species composition and number and the estimated weight of both target species and bycatch, including dolphins. The environmental variables listed above for the fishing sets were also recorded for the sampled sets.

In the present study, we used data collected by the abovementioned program. A total of 2587 longline sets were observed from January to December, between 2000 and 2009. The Spanish longline fishery and the data collection performed by this onboard observer program have been previously described by Camiñas et al. (2006), Báez et al. (2007b), GarcíaBarcelona et al. (2010a,b), Báez et al. (2010, 2011) and Macías et al. (2012).

\subsection{Factors and variables}

We built a distribution model for Risso's dolphin bycatch using variables associated with the following factors: technical characteristics of the fishery, geographic location, and seasonality. Each factor was represented by a set of variables (Table 1).

\section{Technical characteristics of the fishery}

Indicators of the influence of this factor include any positive association with the number of hooks on which dolphins were taken as bycatch. We directly observed the hauling of 5398297 hooks. The following categorical variables were considered: diurnal or nocturnal setting, fishing depth, and gear type. Consistent with García et al. (2010a), we used 5 types of gear as variables. The bottom longline targeting swordfish (LLPB) was excluded from the analysis because no marine mammal bycatch was ever reported for this type of gear. In addition, we used a sixth experimental gear (LLHBexp) because it had a high incidence of marine mammals as bycatch. We also included vessel identification (Vessel identity, VI) as a qualitative (nominal) variable to test if possible differences in fishing practices could be affecting Risso's dolphin bycatch.

\section{Geographic location}

The geographical variables used were the latitudes and longitudes of where setting started (LATSS, LONGSS, respectively) and finished (LATFS, LONGFS, respectively), whether or not the categorical variable fishery operation was on the continental shelf (sets over continental shelf, SCS).

\section{Seasonality}

We tested for the effects of seasonality using the different months as explicative variables. Thus, we used a categorical variable (presence or absence of bycatch) for each observed month. We used months as temporal units, bearing in mind their possible utility for management purposes.

\subsection{Data analysis}

We calculated the rate of total mammal bycatch as the total number of individual mammals caught per thousand hooks deployed (CPUEt) for each type of gear. In addition, we calculated bycatch rates per year (CPUEy) as the total number of individual mammals caught in a year per thousand hooks deployed in that particular year. Thus, the interannual variability of CPUEy could be determined using the Chi-squared test. Subsequently, we calculated the weighted expected bycatch value as the average CPUEt of each type of gear multiplied by the total number of sets observed for this particular type of gear and divided by the total number of sets observed for all the gears together. Standard errors for the entire group of marine mammals, and also for Risso's dolphin alone, were tested to explore patterns in the data. A Chi-squared test (Sokal and Rohlf 1995) was used to determine whether there were statistically significant differences between gears in the number of marine mammals caught.

A possible option for describing bycatch data is a zeroinflated Poisson (ZIP) model, in which data are characterized by having a time series with an excess of zero counts and possibly a large number of captures. However, taking into account the low number of marine mammals caught in the positive events, the ZIP model may not be the best option (Minami et al. 2007; García-Barcelona et al. 2010b). In these cases, Minami et al. (2007) recommended the zero-inflated binomial negative model, whereas several other authors recommended the use of logistic regression for the analysis of captures with a non-normal distributions (Ward et al. 2004; Báez et al. 2007b; Garrison 2007; García-Barcelona et al. 2010a).

We performed a binary logistic regression of the presence and absence of Risso's dolphin bycatch to test whether the 
Table 1. Factors (technical characteristics of the fishery, geographic location and seasonality) and associated variables used to build our predictive model for Risso's dolphin bycatch.

\begin{tabular}{|c|c|c|c|}
\hline Factors & Variables & Variable types & Abbreviation \\
\hline \multirow{8}{*}{$\begin{array}{l}\text { Technical characteristics } \\
\text { of the fishery }\end{array}$} & Vessel identity & Nominal & VI \\
\hline & Number of hooks & Quantitative & $\mathrm{NH}$ \\
\hline & Fishing depth & Binary & FD \\
\hline & Drifting surface longline targeting bluefin tuna & Binary & LLJAP \\
\hline & Home-based surface longline targeting swordfish & Binary & LLHB \\
\hline & American drifting surface longline targeting swordfish & Binary & LLAM \\
\hline & Drifting semi-pelagic longline targeting swordfish & Binary & LLSP \\
\hline & Experimental home-based longline targeting swordfish & Binary & LLHBexp \\
\hline \multirow{5}{*}{ Geographic-location } & Latitude where setting started & Quantitative & LATSS \\
\hline & Longitude where setting started & Quantitative & LONGSS \\
\hline & Latitude where setting finished & Quantitative & LATFS \\
\hline & Longitude where setting finished & Quantitative & LONGFS \\
\hline & Sets over continental shelf & Binary & SCS \\
\hline \multirow{11}{*}{ Seasonality } & February & Binary & $\mathrm{F}$ \\
\hline & March & Binary & MR \\
\hline & April & Binary & AP \\
\hline & May & Binary & MY \\
\hline & June & Binary & $\mathrm{JN}$ \\
\hline & July & Binary & $\mathrm{JL}$ \\
\hline & August & Binary & $\mathrm{AU}$ \\
\hline & September & Binary & S \\
\hline & October & Binary & $\mathrm{O}$ \\
\hline & November & Binary & $\mathrm{N}$ \\
\hline & December & Binary & $\mathrm{D}$ \\
\hline
\end{tabular}

probability of incidentally catching one or more specimens of this marine mammal could be predicted by any of the explanatory variables selected. By performing a logistic regression of the bycatch presence/absence on each variable separately, we identified a subset of variables significantly associated with the distribution of the bycatch. To control for the increase in type I errors due to multiple tests (Benjamini and Hochberg 1995; García 2003), we only accepted those variables that were significant under a False Discovery Rate (FDR) of $q<0.05$ using the Benjamini and Hochberg procedure (1995). We then performed forward stepwise logistic regression on the subset of significant predictor variables to obtain a multivariate logistic model.

Model coefficients were assessed by means of an Omnibus test and the goodness-of-fit between the expected, and observed proportions of bycatch events for ten classes of probability values were evaluated using the Hosmer and Lemeshow test (which also follows a Chi-squared distribution; A $p$ value $<0.05$ would indicate a lack of fit of the model). On the one hand, the Omnibus test determines whether there are significant differences between the -2LL (less than twice the natural logarithm of the likelihood) of the initial step, and the -2LL of the model using a Chi-squared test with one degree of freedom. On the other hand, the Hosmer and Lemeshow test compares the observed and expected frequencies of each value of the binomial variable according to their probability. In this case, we anticipated that there would be no significant differences between them regarding a good model fit.
In addition, the discrimination capacity of the model (trade-off between sensitivity and specificity) was evaluated using the receiving operating characteristic (ROC) curve. The relative importance of each variable within the model was assessed using the Wald test.

Logistic regression (LR) is a widely-used statistical tool for binary distribution models (e.g., Bustamante 1997; Real et al. 2006). Regardless of the goodness-of-fit of the LR model, it is sensitive to the presence/absence ratio (Hosmer and Lemeshow 2000). To solve this problem, Real et al. (2006) introduced a favourability function $(\mathrm{F})$ based on a logistic regression model. This function adjusts the model, regardless of the presence/absence ratio. Favourability was easily calculated from the probability obtained from the LR according to the expression:

$$
F=[P /(1-P)] /\left[\left(n_{1} / n_{0}\right)+(P /[1-P])\right]
$$

where $P$ is the probability of an event occurring, $n_{1}$ is the number of observed presences, and $n_{0}$ is the number of observed absences.

We calculated F from LR, and interpreted it as the extent to which the technical and environmental conditions favour the incidental capture of marine mammals. We used Kendall's $\tau b$ coefficient to correlate each probability and favourability per set with the total number of marine mammal bycatches observed per each fishing operation, excluding the zero. 
Table 2. Cetacean species (number of specimens) caught by the Spanish drifting longline fleet. IUCN status, the number of sets with marine mammal catches and the average number of cetaceans by fishing set are given. The maximum number of cetaceans by set is 3 (Risso's dolphin) and the majority of sets with catches only caught one specimen.

\begin{tabular}{|c|c|c|c|c|c|c|}
\hline \multirow{2}{*}{\multicolumn{2}{|c|}{ Species }} & \multirow{3}{*}{$\begin{array}{l}\text { IUCN status } \\
\text { Least concern }\end{array}$} & \multirow{2}{*}{\multicolumn{2}{|c|}{ Capture of cetaceans }} & \multirow{2}{*}{$\begin{array}{c}\text { Average } \\
\text { cetaceans/set* }\end{array}$} & \multirow{3}{*}{$\begin{array}{r}\text { Range* } \\
1-2\end{array}$} \\
\hline & & & & & & \\
\hline $\begin{array}{l}\text { Short-beaked } \\
\text { common dolphin }\end{array}$ & Delphinus delphis & & $\begin{array}{c}\text { Cetaceans caught } \\
6\end{array}$ & $\begin{array}{c}\begin{array}{c}\text { Sets that caught } \\
\text { cetaceans }\end{array} \\
5\end{array}$ & $1.2( \pm 0.2)$ & \\
\hline Striped dolphin & Stenella coeruleoalba & Least concern & 8 & 8 & $1.0( \pm 0.0)$ & \\
\hline Risso's dolphin & Grampus griseus & Least concern & 33 & 29 & $1.1( \pm 0.1)$ & $1-3$ \\
\hline $\begin{array}{l}\text { Long-finned pilot } \\
\text { whale }\end{array}$ & Globicephala melas & Data deficient & 4 & 4 & $1.0( \pm 0.0)$ & \\
\hline Unidentified marir & nammals & & 6 & 6 & $1.0( \pm 0.0)$ & \\
\hline
\end{tabular}

*Sets with catches.

\subsection{Spatial representation of fishing area and effort}

The geographic coordinates of all fishing operations (setting and hauling) were recorded using a GPS (Datum WGS 84). The starting set point was used to represent fishing effort (number of hooks set). Afterwards, effort values were interpolated to $15 \times 15 \mathrm{~km}$ grids to maintain confidentiality requirements. The marine mammal bycatch of each set was represented using CPUEt (marine mammals per 1000 hooks). Maps were projected in UTM, zone $31 \mathrm{~N}$.

Spatial representations of fishing effort and marine mammal bycatch were made using ESRI ArcView 3.2 software and the Spatial Analyst and Xtools extensions.

\section{Results}

\subsection{Marine mammal bycatch}

A total of 2587 sets were observed from 2000 to 2009. Of these, only 52 fishing operations had interactions with marine mammals. Fifty-seven captures of marine mammals were observed. Four species of cetaceans were identified as part of longline bycatch: 33 Risso's dolphins, 8 striped dolphins, 6 short-beaked common dolphins and 4 long-finned pilot whales (Table 2). Risso's dolphin was the species most frequently affected by this longline fishery. The majority of the catches were recorded beyond the continental shelf, in pelagic waters southwest of the Balearic Islands, and in the North Alboran Sea. The highest observed effort (number of hooks) corresponded to LLHB (59.7\%), followed by LLJAP, LLALB and LLSP (ranging from $10 \%$ to $8 \%$ ). The observed effort of the remaining types of gear used by the fleet did not exceed $6.2 \%$. The total CPUEt for all types of gear and species was 0.011 marine mammals per 1000 hooks. Table 3 shows effort by gear (number of hooks) and annual overall CPUEy of marine mammals.

When possible, the observers collected data on the survival status of the catches. Thus, information was obtained on the health status of the marine mammals in $77 \%$ of the catches: $82 \%$ of the marine mammals were released alive and $18 \%$ died. Table 4 shows the survival rates of cetaceans caught by type of gear used.
Of the 57 observed interactions, there were 38 cases $(67 \%)$ with data on the anatomical location of the hook in the marine mammals caught. Of these, 20 captures (53\%) were hooked at the mouth: 13 Risso's dolphins, 4 striped dolphins and 2 pilot whales. Except for one Risso's dolphin (no data) and one unidentified dolphin (dead), the animals were released alive with hooks (90\%). Of the remaining 18 captures (47\%), hooks were embedded in external parts of the body or catches were tangled with the mainline or hook line: 6 Risso's dolphins, 6 common dolphins, 2 striped dolphins, 2 pilot whales and 2 unidentified dolphins.

The type of gear involving the highest number of incidental catches of marine mammals was LLHB ( $n=25 ; 44 \%)$, followed by LLJAP $(n=16 ; 28 \%)$, then by LLAM and LLSP ( $n=5 ; 18 \%$ for both types of gear). The exploratory analysis showed that there were significant differences between types of fishing gear in the number of marine mammals caught $\left(\lambda^{2}=49.36\right.$, degrees of freedom $\left.6, p<0.05\right)$.

\subsection{Bycatch by type of fishing gear}

LLPB was the only gear without catches of cetaceans and LLALB had a very low CPUEt (0.006 marine mammals per 1000 hooks), mainly affecting striped dolphin (66.7\%) and short-beaked common dolphin $(33.3 \%)$.

LLHB had a CPUEt of 0.008 , slightly higher than that of LLALB. This gear mainly affected Risso's dolphin (36\%), striped dolphin (20\%), common dolphin (20\%), unidentified dolphins (12\%), long-finned pilot whale (8\%) and unidentified marine mammals (4\%). Figure 1A shows the observed effort of LLHB and its corresponding Risso's dolphin catch values. In contrast, LLHBexp had the highest CPUEt (0.059 specimens per 1000 hooks) and only affected Risso's dolphin. Figure 1B shows the observed effort and catches of Risso's dolphins by LLHBexp and its corresponding catch values.

LLAM had a CPUEt of 0.015 marine mammals per 1000 hooks. This gear mainly affected Risso's dolphin (80\%) and, to a lesser extent, striped dolphin (20\%). Figure 1C shows the observed effort of LLAM and its corresponding catch values.

LLSP had a CPUEt of 0.011 marine mammals per 1000 hooks, and mainly affected Risso's dolphin (80\%) and 
Table 3. Effort observed (No. of hooks and No. of sets) per year. Specific gear effort (No. of hooks) and annual CPUEy (No. of cetaceans per 1000 hooks) obtained by gear and year from 2000 to 2009. The greatest percentage of observed effort was LLHB, followed by LLJAP, LLALB, LLSP, LLAM, and LLPB. LLHBexp was only used by part of the fleet during 2003 and its observed effort only represents $0.9 \%$ of the total effort. LLHB, Home-based surface longline targeting swordfish; LLHBexp, Experimental home-based longline targeting swordfish; LLALB, Drifting surface longline targeting albacore; LLPB, Bottom longline; LLAM, American drifting surface longline targeting swordfish; LLSP, Drifting semi-pelagic longline targeting swordfish; LLJAP, Japanese surface longline targeting bluefin tuna.

\begin{tabular}{|c|c|c|c|c|c|c|c|c|c|c|c|}
\hline \multicolumn{3}{|c|}{ Observed effort } & \multicolumn{7}{|c|}{ Observed gear effort } & \multicolumn{2}{|c|}{$\begin{array}{c}\text { Observed capture } \\
\text { of cetaceans }\end{array}$} \\
\hline Year & $\begin{array}{l}\text { No. of } \\
\text { sets }\end{array}$ & $\begin{array}{l}\text { No. of } \\
\text { hooks }\end{array}$ & LLHB & $\begin{array}{l}\text { LLHB } \\
\text { exp* }\end{array}$ & LLALB & LLPB & LLAM & LLSP & LLJAP & $n$ obs. & $\begin{array}{l}\text { Annual } \\
\text { CPUEy }\end{array}$ \\
\hline 2000 & 447 & 1211546 & 1027142 & 0 & 18650 & 18450 & 0 & 0 & 147304 & 8 & 0.007 \\
\hline 2001 & 253 & 709366 & 651774 & 0 & 0 & 2000 & 0 & 0 & 55592 & 3 & 0.004 \\
\hline 2002 & 164 & 514463 & 417007 & 0 & 0 & 39856 & 0 & 0 & 57600 & 7 & 0.014 \\
\hline 2003 & 172 & 351545 & 166020 & 51000 & 0 & 13632 & 47677 & 0 & 73216 & 10 & 0.028 \\
\hline 2004 & 261 & 355594 & 111050 & 0 & 0 & 25676 & 166881 & 0 & 51987 & 6 & 0.017 \\
\hline 2005 & 97 & 112710 & 46828 & 0 & 0 & 0 & 12150 & 0 & 53732 & 1 & 0.009 \\
\hline 2006 & 244 & 514027 & 147340 & 0 & 245488 & 30965 & 72947 & 0 & 17287 & 10 & 0.019 \\
\hline 2007 & 235 & 395145 & 213140 & 0 & 45202 & 81067 & 6957 & 8100 & 40679 & 4 & 0.010 \\
\hline 2008 & 343 & 512911 & 236394 & 0 & 41404 & 34208 & 21878 & 154579 & 24448 & 5 & 0.010 \\
\hline 2009 & 371 & 720990 & 207640 & 0 & 148110 & 54979 & 4400 & 299151 & 6710 & 3 & 0.004 \\
\hline Total & 2587 & 5398297 & & & & & & & & 57 & 0.011 \\
\hline \multicolumn{3}{|c|}{$\begin{array}{l}\text { Percentage of observed } \\
\text { effort }\end{array}$} & 59.7 & 0.9 & 9.2 & 5.6 & 6.2 & 8.6 & 9.8 & & \\
\hline \multicolumn{3}{|c|}{$\begin{array}{c}\text { Capture of cetaceans } \\
\text { observed }\end{array}$} & 25 & 3 & 3 & 0 & 5 & 5 & 16 & & \\
\hline \multicolumn{3}{|c|}{ No. of sets } & 1171 & 23 & 166 & 252 & 300 & 296 & 379 & & \\
\hline
\end{tabular}

* Depth and distance between hooks similar to LLAM.

unidentified dolphins (20\%). Figure 1D shows the observed effort of LLSP and its corresponding Risso's dolphin catch values.

LLJAP had a CPUEt of 0.030 marine mammals per 1000 hooks and mainly affected Risso's dolphin (81.3\%), long-finned pilot whale (12.5\%), and one unidentified dolphin $(6.3 \%)$. Figure 1E shows the spatial distributions of the observed effort for this type of gear and its corresponding CPUEt for Risso's dolphin (specimens per 1000 hooks) per set. Detailed information on CPUEt by species and gear is shown in Table 5 .

There were more marine mammal captures in the late spring and summer seasons (June to September), representing $77 \%$ of the total number of marine mammals caught. There were more incidental catches of Risso's dolphin in June (33\%), followed by August (21\%) and September (18\%). Other catches of Risso's dolphin only occurred in May and July (Fig. 2). The distance from sets with catches to the continent decreased from $82 \mathrm{~km}$ in May to $44 \mathrm{~km}$ in September. The average distance was $76 \mathrm{~km}$ in spring (May and June), and $51 \mathrm{~km}$ in summer (July, August and September). Figure 3 shows a geographic representation of centroids corresponding to polygons generated by sets in which Risso's dolphins were caught each month.

\subsection{Logistic model}

During the 10-year study period, a total of 2335 drifting fishing sets were observed, with a bycatch of 33 Risso's dolphins (GG) in 29 fishing operations (0.0065 GG/1000 hooks).
Table 4. Survival rates of cetaceans caught by gear type. The table shows the number of cetaceans caught by each particular gear and the number of cetaceans released alive or dead. Finally a survival ratio was calculated dividing the number of cetaceans released alive per the total number of cetacean caught by this particular gear. LLALB, Drifting surface longline targeting albacore; LLHB, Homebased surface longline targeting swordfish; LLHBexp, Experimental home-based longline targeting swordfish; LLAM, American drifting surface longline targeting swordfish; LLJAP, Japanese surface longline targeting bluefin tuna; LLSP, Drifting semi-pelagic longline targeting swordfish. LLSP is the gear with the lowest survival ratio.

\begin{tabular}{lcccc}
\hline Gear & $\begin{array}{c}\text { No. } \\
\text { marine } \\
\text { mammals }\end{array}$ & $\begin{array}{c}\text { No. } \\
\text { alive }\end{array}$ & No. dead & Survival rate \\
\hline LLALB & 3 & 3 & 0 & 1 \\
LLHB & 19 & 15 & 4 & 0.79 \\
LLHB exp & 3 & 3 & 0 & 1 \\
LLAM & 5 & 5 & 0 & 1 \\
LLJAP & 9 & 9 & 0 & 1 \\
LLSP & 5 & 1 & 4 & 0.2 \\
\hline
\end{tabular}

We obtained a statistically significant logistic model with the variables LLJAP, LLHBexp, LATSS, and SCS. The model's goodness-of-fit was significant (Omnibus test $=37.63$, $d f=4, p=1.33 \times 10^{-7}$; Hosmer and Lemeshow test $=2.626$, $d f=8, p=0.956)$, and its discrimination capacity was good $(\mathrm{AUC}=0.8)$. The logit function has the form:

$$
\begin{aligned}
y= & -2.87+L L J A P\left\{\begin{array}{l}
N O T=0 \\
Y E S=1.13
\end{array}+L L H B \exp \left\{\begin{array}{l}
N O T=-2.95 \\
Y E S=0
\end{array}\right.\right. \\
& +L A T S S^{*}-0.39+S C S\left\{\begin{array}{l}
N O T=16.23 \\
Y E S=0
\end{array} .\right.
\end{aligned}
$$



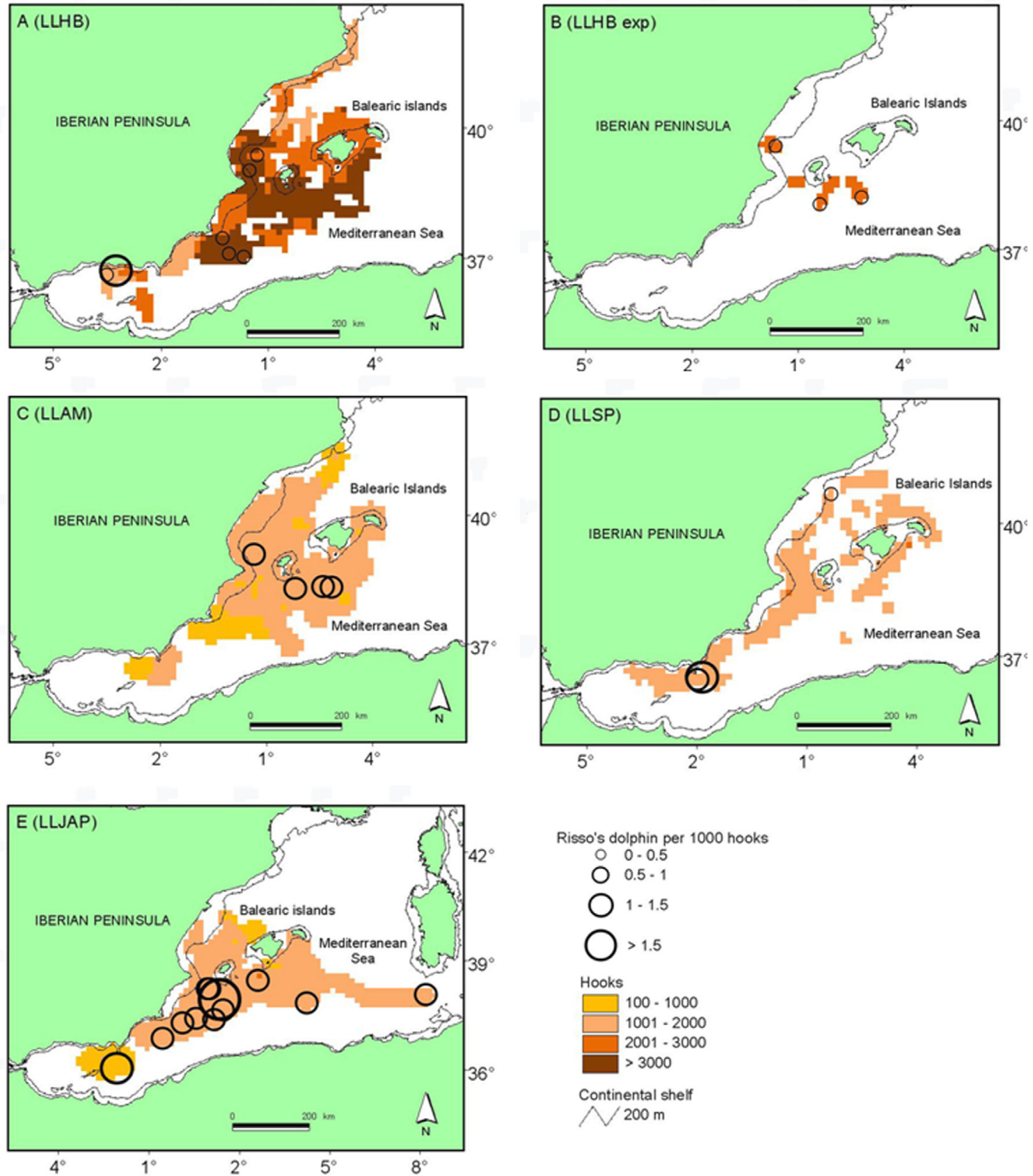

Fig. 1. Fishing grounds and geographical distribution of effort and catches of Risso's dolphin (specimens per 1000 hooks) found in this study. A: Observed effort of LLHB (home-based surface longline targeting swordfish) and its corresponding Risso's dolphin catch values. B: the same results for LLHBexp (experimental home-based longline targeting swordfish); this gear had the highest Risso's dolphin CPUEt found in this study. C: observed effort of LLAM (American drifting surface longline targeting swordfish) and its corresponding Risso's dolphin catch values. D: our results on LLSP (drifting semi-pelagic longline targeting swordfish) and its corresponding Risso's dolphin catch values. E: Spatial distributions of the observed effort for LLJAP (Japanese surface longline targeting bluefin tuna) and its corresponding cetacean CPUEt per set.

Table 6 shows the Wald parameter, observed frequency and categorical variables coding in the logit function.

The other tested variables (including VI) were not selected by the mathematical algorithms used because none of them contributed significantly to the general model. This implies that there were no significant differences in fishing practices between vessels and that the predictive model was not changed by taking into account the variable VI.
We obtained a significant $\mathrm{F}$ function from $\mathrm{P}$ and a significant Kendall's $\tau$ b correlation between the favourability per set higher than 0.5 versus the total number of Risso's dolphins observed per each fishing operation (Kendall's $\tau \mathrm{b}$ coefficient $=$ $0.1, p=0.001)$. This suggests that these factors not only affect the probability of catching Risso's dolphin as opposed to not catching them, but also the number of Risso's dolphin captures in a specific set. 
Table 5. Cetacean bycatch CPUEt (number of cetaceans per 1000 hooks) reported by species and gear type. LLALB, Drifting surface longline targeting albacore; LLJAP, Japanese surface longline targeting bluefin tuna; LLHB, Home-based surface longline targeting swordfish; LLHBexp, Experimental home-based longline targeting swordfish; LLPB, Bottom longline; LLSP, Drifting semi-pelagic longline targeting swordfish. LLAM, American drifting surface longline targeting swordfish.

\begin{tabular}{lccccc}
\hline & $\begin{array}{c}\text { Delphinus } \\
\text { delphis }\end{array}$ & $\begin{array}{c}\text { Striped } \\
\text { dolphin }\end{array}$ & $\begin{array}{c}\text { Risso's } \\
\text { dolphin }\end{array}$ & $\begin{array}{c}\text { Globicephala } \\
\text { melas }\end{array}$ & $\begin{array}{c}\text { CPUEt Total } \\
\text { (including } \\
\text { unidentif. mar. } \\
\text { Mammals) }\end{array}$ \\
\hline LLALB & 0.0020 & 0.0040 & 0 & 0 & 0.0060 \\
LLJAP & 0 & 0 & 0.0246 & 0.0038 & 0.0303 \\
LLHB & 0.0015 & 0.0016 & 0.0028 & 0.0006 & 0.0077 \\
LLHB exp & 0 & 0 & 0.0588 & 0 & 0.0588 \\
LLPB & 0 & 0 & 0 & 0 & 0 \\
LLSP & 0 & 0 & 0.0087 & 0 & 0.0108 \\
LLAM & 0 & 0.0030 & 0.0120 & 0 & 0.0150 \\
\hline
\end{tabular}

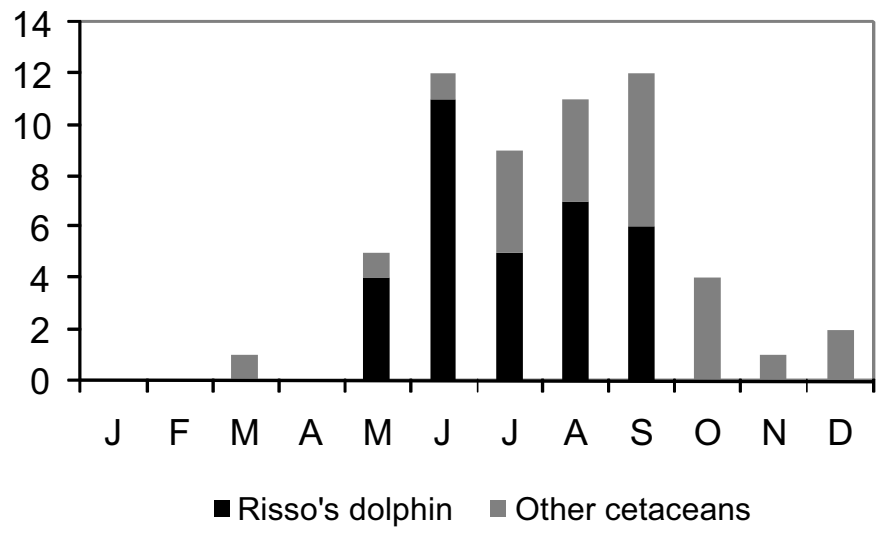

Fig. 2. Monthly frequency of marine mammal bycatch showing proportion of Risso's dolphins during the study period (2000-2009). The marine mammal bycatch occurs mainly in spring and summer. Risso's dolphin captures are concentrated in spring (May-June) and summer (July-September), with a peak in June.

\section{Discussion}

Our data indicate that the number of incidental marine mammals per set caught by Spanish drifting longline fisheries in the western Mediterranean is less than that in other fisheries, such as purse seine and trawl (Crespo et al. 1997, in Bearzi 2002; Tudela 2004). In a manner consistent with Camiñas and Valeiras (2001), we observed a low bycatch per unit effort (0.011 marine mammals/1000 hooks) compared to other bycatch species, such as sharks (Macías et al. 2004), seabirds (García et al. 2010a) and sea turtles (Camiñas et al. 2006). Camiñas and Valeiras (2001) observed that Risso's dolphins and striped dolphins were the main species in the bycatch of these fisheries in the same area. In our study, the type of gear with the highest number of incidental catches of marine mammals was LLHB ( $n=25 ; 44 \%)$, mainly affecting dolphins (52\%), but also Risso's dolphin (36\%). This was followed by LLJAP ( $n=16 ; 28 \%$ ), which mainly affected Risso's dolphin $(81 \%)$. LLAM and LLSP had less impact on marine mammals. LLPB was the only type of gear that did not catch any marine mammals, probably because these species do not usually capture their prey at the depths $80-400 \mathrm{~m}$ or in the places in which
Table 6. Wald parameters of the variables included in the predictive model. Of the three binary variables included in the model, we also show the binary state (Yes or No) and the observed frequency of each binary state. Key: LLJAP, Japanese surface longline targeting bluefin tuna; LLHBexp, Experimental home-based longline targeting swordfish; LATSS, Latitude where the set was started; SCS, Sets over continental shelf. ${ }^{1}$ Wald parameters $p<0.05 .{ }^{2}$ Wald parameters $p>0.05$.

\begin{tabular}{lccc}
\hline $\begin{array}{l}\text { Variable } \\
\text { abbreviation }\end{array}$ & $\begin{array}{c}\text { Wald } \\
\text { parameter }\end{array}$ & Category & $\begin{array}{c}\text { Observed } \\
\text { frequency }\end{array}$ \\
\hline LLJAP & $7.99^{(1)}$ & NO & $\begin{array}{c}2312 \\
23\end{array}$ \\
\hline LLHBexp & $18.15^{(1)}$ & NOS & $\begin{array}{c}1956 \\
\text { YES }\end{array}$ \\
\hline LATSS & $4.47^{(1)}$ & - & - \\
\hline SCS & $9.5 \times 10^{-5(2)}$ & NO & $\begin{array}{c}1743 \\
\text { YES }\end{array}$ \\
\hline
\end{tabular}

this gear is used. The differences observed between types of gear could be partly related to the depths in which each type of gear is used and also the type of bait: cephalopods are used in LLJAP, whereas mainly sardine and mackerel are used in other types of gear.

The most common species caught by the longline fisheries in the western Spanish Mediterranean are Risso's dolphin. Our results also indicate that the impact of pelagic and semi-pelagic longlines on Risso's dolphin is particularly low (0.007 dolphins per 1000 hooks). LLJAP was the only gear with a major impact on Risso's dolphin (0.025 dolphins per 1000 hooks). These low Risso's dolphin longline bycatch rates are consistent with those observed in previous studies (Di Natale 1990; Mussi et al. 1998; Bearzi 2002; Garrison 2007).

Regarding the survival of marine mammal species, cetaceans have a high probability of survival if they are hooked on the hooks closest to the floats: this is also the case for sea turtles (e.g., Camiñas et al. 2006). Our results show (Table 4) that the deepest gears (LLSP) are fatal to marine mammals because they cannot get to the surface to breathe. Normally, fishermen cut the hook line near the mouth or body when a hooked marine mammal appears during hauling. It is released with the hook remaining in the mouth or the body with less 


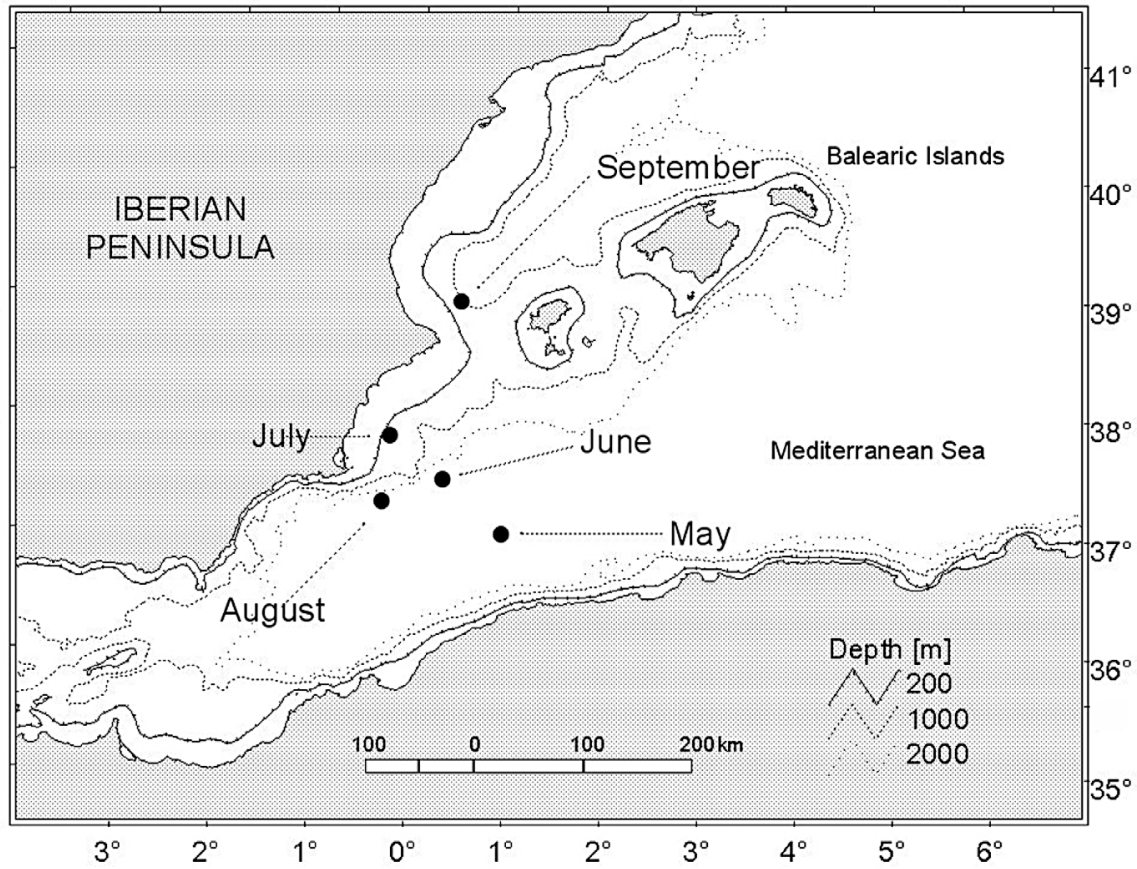

Fig. 3. Centroids corresponding to polygons generated for each month when there were catches of Risso's dolphin. In general, in spring (MayJune) Risso's dolphin interacts with fishing gears in oceanic waters but in summer (July-September) catches occur near to the continental slope.

than $1 \mathrm{~m}$ of monofilament line attached. Fishermen should be trained to remove as much of the line as possible, as this reduces the level of injury. The injuries to Risso's dolphin caused by monofilament lines and hooks could be a significant conservation concern.

In our predictive model on Risso's dolphin bycatch, the factor "technical characteristics of the fishery" had two explanatory variables: LLHBexp and LLJAP. Similarly, the factor "geographic location" had two explanatory variables in the model: LATSS and SCS (see Table 6). The factor "seasonality" had no explanatory variable in the model.

Interactions between Risso's dolphin and the fisheries were correlated with geographic location, proximity to the shelf break, the length of the main line and bait type (Bearzi, et al. 2011). The most important variable affecting Risso's dolphin bycatch in the F model (according to Wald's parameter; Table 6), was LLHBexp. This variable has the highest explanatory power, but only a low impact on the species in reality because this gear only was occasionally used by the fleet in 2003. If we remove LLHBexp from the F model, LLJAP replaces LLHBexp as the variable with the highest explanatory power.

Regarding geographical location, latitude (LATSS) was an important explanatory variable in our model, which is consistent with the majority of biogeographic studies. However, we cannot clarify the nature of these associations. Thus, this geographic component could be considered a set of macroecological variables. In our model, the variable SCC has low explanatory power and could be indicative of the seasonal behaviour of Risso's dolphin. According to some authors, Risso's dolphins inhabit waters of the continental slopes in late summer, whereas they prefer oceanic waters in late spring. Some authors also suggest that this type of nomadic behaviour could be related to feeding habits, including benthic resources (certain species of cephalopods) (Würtz et al. 1992; Mangion 2002; Blanco 2006). In this sense, our results show that Risso's dolphins tend to come closer to the continental slopes in summer. The average distance from sets to the continent in the summer months (July-September) was less than that in the spring months (May-June). The variable SCC could also reflect the absence of effort of LLJAP in the summer period, since LLJAP was only used by the fleet from May to July and mainly in the open seas (García-Barcelona 2010a).

The other technical characteristics of the gear that correlated with Risso's dolphin interactions were the length of the main line and bait type (Bearzi et al. 2011). Both characteristics are included in the definition of gear type. We suggest that the following factors, which are intrinsic to LLJAP and LLHBexp, could determine the impact of this gear on Risso's dolphin:

a) The length of the mainline. This variable has been reported to affect marine mammal bycatch in other fisheries (Garrison 2007). Our results are consistent with this because LLJAP operates with the longest mainline of the type of gear with cetacean bycatch (LLHB, LLSP). A longer mainline could present a larger, more attractive food source or it could be more easily detected (Garrison 2007).

b) The time that gear remains in the water. The longer the line remains in the water, the more easily it is detected. In addition, Risso's dolphin seems to feed predominantly at night (Soldevilla et al. 2010). Thus, there may be an increased probability of overlap between feeding time and the time 
that gear remains in the water. The time that the hooks remained in the water in LLJAP was higher than LLHB, but similar to LLSP (24-36 hours).

c) The bait. Each gear used a specific type and size of bait. Large squid Illex sp. $( \pm 500 \mathrm{~g})$ is the most common bait in LLJAP and LLHBexp. Risso's dolphin predominantly consume cephalopods, mainly mesopelagic squid (Blanco 2006; Clarke 1996; Oeztuerk et al. 2007; Würtz et al. 1992); the use of fish as bait significantly decreases Risso's dolphin bycatch (Garrison 2007). In total, 13 Risso's dolphins were hooked at the mouth. Many hooks have luminescent lures which may increase their attractiveness to Risso's dolphin. Given that many of the cephalopods identified as being consumed by these dolphins are bioluminescent, the dolphins may use bioluminescence to target the cephalopods (Oeztuerk et al. 2007).

d) Working depth of hooks. LLJAP and LLHBexp can operate at a depth of around 50-100 m. Normally, there are 4 hooks between floats, at a distance of $50-70 \mathrm{~m}$ from each other. The hook line is usually $22 \mathrm{~m}$ long. When added to the line of the float, the hooks have a wide range of working depths. Numerous species of cephalopods are present in this depth range (Sánchez 1996). Some of these, such as Illex coindetti, Eledone cirrhosa and Todarodes sagittatus, are commonly found the stomachs of Risso's dolphin in the western Mediterranean (Blanco 2006). It would appear that the habitats of oceanic cephalopods and their behaviour, with their wide vertical distribution and circadian movements, coincide with the fishery area of some gears, mainly LLJAP.

According to our model, the most important factors for management applications are the technical characteristics of the fishery and its geographic location. Our results indicate that Risso's dolphin was mainly caught by the LLJAP and LLHBexp over the continental shelf. Reducing the effort of these types of gear and limiting the fishing sets to oceanic areas could improve the conservation of Risso's dolphin populations in the western Mediterranean. However, due to the low explicative power of the variable SCC in our model, limiting the fishing activity to oceanic areas would not substantially reduce the bycatch of this species. Nevertheless, LLHBexp is rarely used by the fleet and the TACS and quotas recently adopted to manage the bluefin tuna stocks have severely reduced the effort of LLJAP in the Spanish Mediterranean. It would be of interest to test our model using data from next year to confirm our conclusions. According to our model, we would expect a strong reduction in interactions between the Spanish longline fishery and the Risso's dolphin, which would be mainly due to the reduction in the LLJAP fishing effort.

In conclusion, the reduction in the LLJAP fishing effort, which is mainly due to the ICCAT bluefin tuna recovery plan, has substantially reduced the impact of Spanish Mediterranean longline fisheries on marine mammals, particularly on Risso's dolphin. In the light of these changes, we will conduct future studies to address the issue of whether other types of gear, such as LLSP, could represent a serious threat to the species.

Acknowledgements. The Onboard Observer Program in commercial longline fisheries was supported by different projects from the
Oceanographic Centre of Malaga of the IEO (Spanish Institute of Oceanography). We are grateful to the boat crews and skippers who worked voluntarily with the Onboard Observer Program, the observers of the IEO, and our colleagues at the Large Pelagic Fisheries Department at Malaga for their assistance with data collection.

\section{References}

Báez J.C., Real R., Camiñas, J.A., 2007a, Differential distribution within longline transects of loggerhead and swordfish captured by the Spanish Mediterranean surface longline fishery. J. Mar. Biol. Assoc. UK 87, 801-803.

Báez J.C., Real R., García-Soto C., de la Serna J.M., Macias D., Camiñas J.A., 2007b, Loggerhead turtle by-catch depends on distance to the coast, independent of fishing effort: implications for conservations and fisheries management. Mar. Ecol. Prog. Ser. 338, 249-256.

Báez J.C., Real R., Camiñas J.A., Torreblanca D., Garcia-Soto C., 2009, Analysis of swordfish catches and by-catches in artisanal longline fisheries in the Alboran Sea (western Mediterranean Sea) during the summer season. Mar. Biodiv. Rec. 2, e157, doi: $10.1017 /$ S1755267209990856.

Báez J.C., Real R., Bellido J.J., Macias D., de la Serna J.M., Camiñas, J.A., 2011, Validating an ecological model with fisheries management applications: the relationship between loggerhead bycatch and distance to the coast. J. Mar. Biol. Assoc. UK 91, 1381-1383.

Báez J.C., Real R., Macias D., de la Serna J.M., Bellido J.J., Camiñas J.A., 2010, Swordfish Xiphias gladius Linnaeus 1758 and loggerhead Caretta caretta (Linnaeus 1758) captures associated with different combinations of bait in the western Mediterranean surface longline fishery. J. Appl. Ichthyol. 26, 126-127.

Blanco, C. Raduan M.A., Raga J.A., 2006, Diet of Risso's dolphin (Grampus griseus) in the western Mediterranean Sea. Sci. Mar. 70, 407-411.

Baird R.W., 2002, Risso's dolphin. In: Perrin W.F., Würsig B., Thewissen J.G.M. (Eds.) Encyclopedia of marine mammals. San Diego, Academic Press, pp. 1037-1039.

Bearzi G., Reeves R.R., Remonato E., Pierantonio N., Airoldi S., 2011, Risso's dolphin Grampus griseus in the Mediterranean Sea. Mammal Biol. 76, 385-400.

Benjamini Y., Hochberg Y., 1995, Controlling the false discovery rate: a practical and powerful approach to multiple testing. J. R. Stat. Soc. B 57, 289-300.

Bierzi G., 2002, Interactions between cetacean and fisheries in the Mediterranean Sea. In: Notarbartolo di Sciara (Ed.), Cetaceans of the Mediterranean and Black Seas: state of knowledge and conservation strategies. A report to the ACCOBAMS Secretariat, Monaco 9, 20 p.

Camiñas J.A., Báez J.C., Valeiras J., Real R., 2006, Differential loggerhead by-catch and direct mortality in surface longline according to boat strata and gear type. Sci. Mar. 70, 661-665.

Camiñas J.A., Valeiras J., 2001, Marine turtles, mammals and sea birds captured incidentally by the Spanish surface longline fisheries in the Mediterranean Sea. Rapp. Comm. Int. Mer Médit. 36, 248.

Clarke, M.R., 1996, Cephalopods as prey. III. Cetaceans. Phil. Trans. R. Soc. Lond. Ser. B 351, 1053-1065.

Crespo E.A., Pedraza S.N., Dans S.L., Koen Alonso M., Reyes L.M., García N.A., Coscarella M., Schiavini A.C.M., 1997, Direct and indirect effects of the high seas fisheries on the marine mammal population in the northern and central Patagonian coast. J. Northwest Atl. Fish. Soc. 22, 189-207. 
Di Natale A., 1990, Interaction between marine mammals and Scombridae fishery activities: The Mediterranean case. FAO Fish. Rep. 449, 167-174.

Duguy R., Casinos A., Di Natale A., Filella S., Ktari-Chakroun F., Lloze R., Marchessaux D., 1983a, Répartition et fréquence des mammifères marins en Méditerranée. Rapp. Comm. Int. Mer Médit. 28, 223-230.

Duguy R., Besson J., Cassinos A., Di Natale A., Filella S., Raduan A., Raga J., Viale D., 1983b, L'impact des activités humaines sur les cétacés de la Méditerranée occidentale. Rapp. Comm. Int. Mer Médit. 28, 219-222.

García L.V., 2003, Controlling the false discovery rate in ecological research. Trends Ecol. Evol. 18, 553-554.

García-Barcelona S., Ortiz de Urbina J.M., de la Serna J.M., Alot E., Macias D., 2010a, Seabird by-catch in Spanish Mediterranean large pelagic longline fisheries, 1998-2008. Aquat. Living Resour. 23, 363-371.

García-Barcelona S., Macías D., Ortiz De Urbina J.M., Estrada A., Real R., Báez J.C., 2010b, Modelling abundance and distribution of seabird by-catch in the Spanish Mediterranean longline fishery. Ardeola 57, 65-78.

Gerrodette T., Forcada J., 2005, Non-recovery of two spotted and spinner dolphin populations in the eastern tropical Pacific Ocean. Mar. Ecol. Prog. Ser. 291, 1-21.

Garrison L.P., 2007, Interactions between marine mammals and pelagic longline fishing gear in the U.S. Atlantic Ocean between 1992 and 2004. Fish. Bull. 105, 408-417.

Gomez de Segura A., Crespo E.A., Pedraza S.N., Hammond P.S., Raga J.A., 2006, Abundance of small cetaceans in waters of the central Spanish Mediterranean. Mar. Biol. 150, 149-160.

Hosmer D.W., Lemeshow S., 2000, Applied logistic regression, 2nd edn. New York, John Wiley and Sons, Inc.

Jefferson T.A., Leatherwood S., Webber M.A., 1993, FAO Species identification guide. Marine mammals of the world. UNEP/FAO. Rome.

Macias D., Báez J.C., García S., Ortíz De Urbina J.M., 2012, Dolphinfish bycatch in Spanish Mediterranean large pelagic longline fisheries, 2000-2010. Scient. World J. doi:10.1100/2012/104389.

Macías D., Gómez-Vives M.J., de la Serna J.M., 2004, Desembarcos de especies asociadas a la pesquería de palangre de superficie dirigido al pez espada (Xiphias gladius) en el Mediterráneo durante 2001 y 2002. ICCAT Col. Vol. Sci. Pap. 56, 981-986.

Mangion P., Gannier A., 2002, Improving the comparative distribution picture for Risso's dolphin and long-finned pilot whale in the Mediterranean Sea. Eur. Res. Cetaceans 16, 68.

Minami M., Lennert-Cody C.E., Gao W., Román-Veredesoto M., 2007, Modeling shark bycatch: The zero-inflated negative binomial regression model with smoothing. Fish. Res. 84, 210-221.

Mussi B., Gabriel R., Miragliuolo A., Battaglia M., 1998, Cetacean sightings and interactions with fisheries in the archipielago Pontino Campano, southern Tyrrhenian Sea, 1991-1995. Eur. Res. Cetaceans 12, 63-65.

Oeztuerk B., Salman A., Oeztuerk A.A., Tonay A., 2007, Cephalopod remains in the diet of striped dolphins (Stenella coeruleoalba) and Risso's dolphins (Grampus griseus) in the eastern Mediterranean Sea. Vie Milieu 57, 53-59.

Real R., Barbosa A.M., Vargas J.M., 2006, Obtaining environmental favourability functions from logistic regression. Environ. Ecol. Stat. 13, 237-245.

Sánchez P., 1986, Distribución batimétrica y abundancia de algunos cefalópodos del mar Catalán. Invest. Pesq. 50, 237-245.

Sokal R.R., Rohlf F.J., 1995, Biometry. 3rd edn., New York, W.H. Freeman and Co.

Tudela S., 2004, Ecosystem effects of fishing in the Mediterranean: an analysis of the major threats of fishing gear and practices to biodiversity and marine habits. General Fisheries Commission for the Mediterranean (FAO), Stud. Rev. 74, FAO, Rome.

University of Barcelona, 1995, A survey of interactions between marine mammals and fisheries in the south western waters of the EEC (SUROESTE). Final Report to the General Directorate for Fisheries, EC DGXIV. Project PEM/92/3507.

Valeiras J., Camiñas J.A., 2003, The incidental capture of seabirds by Spanish drifting longline fisheries in the western Mediterranean Sea. Sci. Mar. 67, 65-68.

Ward P., Myers R.A., Blanchard W., 2004, Fish lost at sea: the effect of soak time on pelagic longline catches. Fish. Bull. 102, 179-195.

Würtz M., Poggi R., Clarke M. R., 1992, Cephalopods from the stomach of a Risso's dolphin (Grampus griseus) from the Mediterranean. J. Mar. Biol. Assoc. UK 72, 861-867. 